\title{
Pre-Service Elementary Teachers’ Knowledge of Linear Function and Slope
}

\author{
Yea-Ling Tsao \\ Minnesota State University, Mankato, USA
}

This study aimed to investigate pre-service elementary teachers' performance and understanding of slope and linear function. Pre-service elementary teachers' content, knowledge, and perceptions about representations of linear functions are a major factor that affects students' concept building and learning processes. This study reports pre-service elementary teachers' misconceptions and limited understanding of linear functions and slope. The findings intended to pinpoint the participating pre-service elementary teachers' knowledge regarding linear function and slope. Forty-three pre-service elementary teachers in South Minnesota participated for Diagnostic Test (DT). The DT included six categories as determine the slope, determine points on the linear function, find linear function by using points, determine linear function with perpendicular line, determine linear function with parallel line, and understand properties of linear function and slope. Thirteen items were compiled into six categories with distinctive attributes in relation to linear function and slope. Derived from the DT, average number of items correctly answered by pre-service elementary teachers is 5.53 ; the percentage of correctly responses is $42.53 \%$. In this study, a passing benchmark of $70 \%$ was considered to assess participants' content competency as a qualified elementary teacher's licensure for Minnesota Essential Academic Skills with Math. When 70\% (9 items) of correctness was used as the passing rate of this instrument, only $11.6 \%$ of the pre-service teachers reached that standard. Overall, the pre-service elementary teachers performed rather inadequately on the DT. The data shows that the percent of correct response of determining linear function with perpendicular line $10.47 \%$, determining linear function with parallel line $20.07 \%$ of DT was relatively low when compared with find linear function by using points $60.46 \%$, understand properties of linear function and slope 53.37\%. The findings of study suggest that pre-service elementary teachers exhibit difficulties with transformation between graphical and algebraic representations of slopes that may be indicative of a lack of conceptual understanding of the meaning and properties of slope. The data also reveals that pre-service teachers had difficulties with determining linear function with perpendicular line, determining linear function with parallel lines, and understand properties of linear functions. The results suggested that the participating teacher candidates possessed a poor understanding of content knowledge in this significant content area, which may point to unsuccessful performance on the upcoming certification test and in subsequent teaching practice.

Keywords: linear function, slope, pre-service elementary teachers, mathematics education

\section{Introduction}

It is important for all school-aged students to learn algebra, including the ability to generalize and to 
function in our increasingly complex world (National Council of Teachers of Mathematics [NCTM], 2000). Pre-service elementary teachers play a critical role in initiating and developing algebraic reasoning in grades K-6, conversely teachers' weak conceptual understanding of crucial subject-matter knowledge is well known (Ma, 1999). Research has suggested that teachers' comprehensive knowledge has significant impact on students' achievement in mathematics. There is a correlation between teachers' content knowledge and students' knowledge of mathematics (Hill, Rowan, \& Ball, 2005; Ma, 1999). Without the prerequisite content knowledge on the part of pre-service elementary teachers, meeting these objectives for students is questionable. Pre-service elementary teachers' content knowledge and perceptions about representations of linear functions is a major factor that affects students' concept building and learning processes. However, the research base of pre-service teachers' knowledge regarding algebra is rather limited (She, Matteson, Siwatu, \& Wilhelm, 2014). To successfully help students' understanding of algebra, teachers themselves must have an in-depth knowledge of the subject.

Pre-service teachers' understanding of linear functions and slope has received relatively limited attention from the current research in mathematics education. In other words, teacher education programs need to support pre-service teachers in building solid content knowledge, which may then result in a positive effect on student learning. Educator preparation programs must provide the content background to support pre-service teachers in their understanding of algebra in particular.

There are three reasons for choosing these two concepts as a topic for exploration with pre-service elementary teachers. First, slope and linear function requires an integrated mastery of basic algebraic and geometric concepts, such as equations, variables, and attributes of linear lines. Second, a conceptual understanding of slope and linear function is especially crucial for the study of advanced algebra, calculus, and other higher-level mathematics. Third, pre-service elementary teachers are likely to encounter the concepts of linear function and slope for the licensure math exam. A thorough investigation of the sophisticated connection between linear function and slope may help to provide insights into pre-service elementary teachers' strengths and weaknesses in relevant mathematical content knowledge.

\section{Background and Perspectives}

Great numbers of attention focused to multi-representations of linear functions, such as graphs, tables, and symbols, carry great significance in various contexts, including medicine, business, and engineering. Furthermore, NCTM (2000) explained that knowledge of functions is a central component of learning about algebra that should be highlighted throughout students' school years beginning in the elementary grades. Linear function and slope are central mathematical ideas, after being added to high schools' graduation requirements, particularly for all college-bound students, algebra has gained momentum in its importance as a mathematics course. Conceptual understanding of algebra and in particular linear functions involves the use of the language of mathematics with emphasis on manipulating symbols and graphic representations. Regardless of the form, the rate of change of a function is the ratio of change in the dependent variable to the change in the independent variable. This is the same ratio as is used to represent slope. Thus, although slope has its reference in geometry, slope is rate of change and thus it also has meaning in formulae, tables, physical situations, and verbal descriptions. Research has discovered difficulties that students have with the concept of slope. There are misconceptions associated with the calculation of slope and with the interpretation of linear functions and their graphs (Barr, 1981; Schoenfeld, Smith, \& Arcavi, 1993). Acuna (2007) determined that most 10th-grade 
students had difficulties in predicting or explaining about the graphical representation of the slope of linear function. Zaslavsky, Sela, and Leron (2002) pointed out that some 11th-grade students have experienced much confusion regarding the connections between the algebraic and geometric aspect of slope, scale, and angle.

Early research has discovered students' errors, conceptions, and misconceptions in linear functions and their graphs (Acuna, 2007; Davis, 2007; Knuth, 2000; Nathan\& Kim, 2007; Rider, 2004; Zaslavsky et al., 2002).

Only a few studies have investigated pre-service teachers' understandings in relation to linear function and slope. Ball (1988) and Zaslavsky et al. (2002) identified that pre-service teachers possessed poor background with this topic but failed to implement an integral investigation regarding teachers' understanding of the attributes of linear functions. However, several investigations (Even, 1993; Norman, 1992; Wilson, 1994, She et al., 2014) have explored various aspects of pre-service and in-service teachers' knowledge of function. Zaslavsky et al. (2002) examined a diverse group of individuals' understanding of slope, the study focused on whether participants could identify the properties of the same linear function in homogeneous and non-homogeneous coordinate systems. The results of the study indicated that only $24 \%$ of the total participants and $32 \%$ of the pre-service teachers could provide the correct answers. Furthermore, Stump (1996) and She et al. (2014) also found that secondary mathematics teachers' and pre-service teachers' conception of slope was limited. They perceived slope mostly in geometric means and had a scarce understanding of algebraic, trigonometric, and functional representations. Slope is thus considered a fundamental concept with many representations (e.g., geometric, algebraic, trigonometric, and functional). It is a deep mathematical idea that threads its way throughout the curriculum, closely tied to the notion of function. Specifically, the researchers needed to pursue the pre-service teachers' understandings regarding the relationships between a given linear function and its slope, two parallel or perpendicular slopes, what points constitute a linear function and the nature of pre-service teachers' knowledge and understanding of slope and linear function.

Clarifying pre-service teachers' responses to questions focusing on these concepts, as well as acquiring a better understanding of pre-service teachers' content knowledge, is the motivation for the present study. To meet the goals of teaching algebraic reasoning in the elementary school curriculum, we need to understand more about how pre-service teachers need to be prepared for this undertaking. This study anticipated to comprehensively discover the participating pre-service teachers' knowledge regarding linear function and slope. The following research questions guided the investigation:

1. What is pre-service elementary teachers' performance and understanding of slope and linear function?

2. What is the nature of pre-service elementary teachers' difficulties about slope and linear function?

\section{Sample and Procedure}

All participants $(N=43)$ were pre-service teachers seeking Elementary and Early Childhood through Grade 6 (K-6 licensure) teacher certification from a teacher education program at a mid-sized, four-year state university in a mid-sized town in the Southern Minnesota. All participants are required to take nine hours of mathematics: Elements of Mathematics I, Elements of Mathematics II, and Elements of Mathematics III. These three courses together are framed around the state content standards for mathematics. The sample was composed of students in two sections of the third of three-mathematics methods course. At the time of the study, all participants had successfully completed Elements of Mathematics I and Elements of Mathematics II and were enrolled in Mathematics for Elements of Mathematics III. Forty-three participants from these two classes 
completed data collection tasks during the Spring 2017 semester for the study. Among the 43 participants, nine were male and 34 were female.

The participants in this study were not randomly selected. They were members of two sections of Elements of Mathematics III pre-service teachers taught by the researcher as a full-time faculty member. At the beginning of one class period, students were asked for the voluntary participation in a study about algebra. They were assured that participation was voluntary and anonymous and would in no way influence their grade. The participants were given the Diagnostic Test (DT) and given approximately 30 minutes to respond and show their works as well. In order to pinpoint participants' deficiencies and misconceptions correspondingly, both individual items and clustered category descriptive data reports were analyzed. To further probe, the extent to pre-service teachers grasped those relevant ideas, and possible factors contributing to their incompetence in this regard, examining and analysis of participants' work played a significant role in providing explanations.

\section{Instruments and Data Collection}

The DT data used in this study consisted of 13 multiple choices questions. Table 1 shows six sample items of DT. The DT was developed by adapting questions from She et al. (2014). The test instrument questions were intended to test different categories. The DT includes six categories as determining the slope, determining points on the linear function, finding linear function by using points, determining linear function with perpendicular line, determining linear function with parallel lines, and understanding properties of linear function and slope. Thirteen items were composed into six categories with distinct attributes in relation to linear function and slope. All the items were carefully chosen and revised to match the testing scope of this study and two expert professors in the field of mathematics education were used to assess the content validity of the instrument.

Table 2 provides the framework of DT items by categories. The 13-item DT was designed to measure the performance and understanding of slope and linear function of pre-service teachers. Numeric data was collected with respect to participating pre-service teachers' particular performance and understanding in terms of linear function and slope by administering the DT instrument to participants.

Higher scores on the DT indicate higher subject matter knowledge level toward linear function and slope. A measure of internal consistency was calculated for the DT, the Cronbach's alpha reliability coefficient for the DT was 0.76. A Cronbach's alpha of 0.76 implied a somewhat low reliability of the instrument for two reasons: (a) insufficient number of participants; and (b) inadequate number of test items were given to students. Numeric data was collected with respect to participating pre-service teachers' particular knowledge and understanding in terms of linear function and slope by administering the DT instrument to participants. The 13 multiple-choice questions on the DT assessed the pre-service teachers' mastery of content knowledge and were evaluated quantitatively. Each correct answer was scored as "1" point respectively. In contrast, an incorrect answer was counted as "0" point. The percentage of the individual's total score against the overall 13 points reflected the pre-service teacher' subject matter knowledge level. Both individual items and clustered category descriptive data reports were examined. In order to pinpoint participants' deficiencies and misconceptions correspondingly, the researcher request the participants answer the test, but also show their works for examining and analysis of participants’ work played a significant role in providing explanations. 
Table 1

Sample of Items

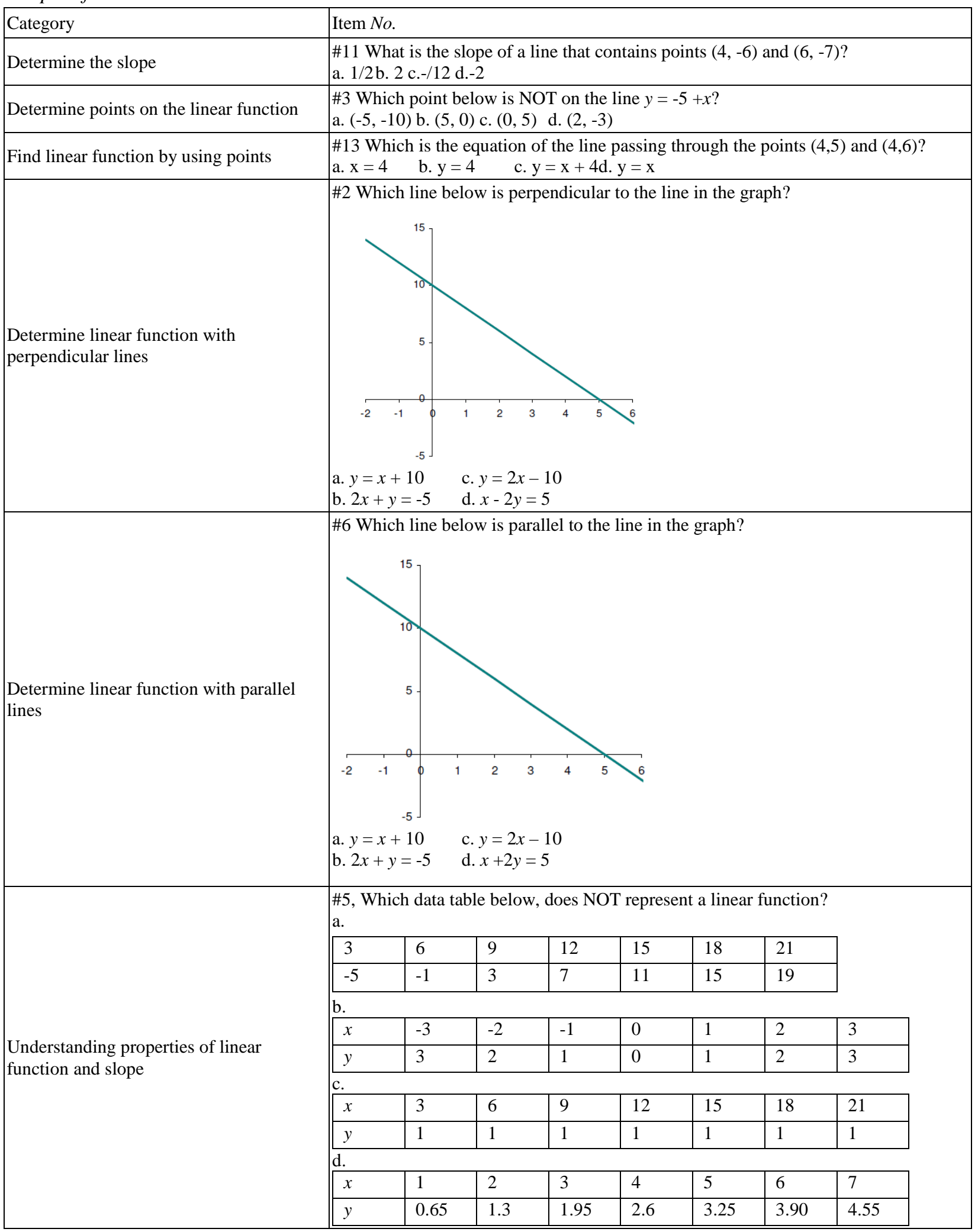


Table 2

\begin{tabular}{lll}
\multicolumn{2}{l}{ Categories of Item Distribution } & \\
\hline Category & Category concept & Test item Nos. \\
\hline 1 & Determine the slope & 9,11 \\
2 & Determine points on the linear function & 3,7 \\
3 & Find linear function by using points & 10,13 \\
4 & Determine linear function with perpendicular line & 1,2 \\
5 & Determine linear function with parallel line & 4,6 \\
6 & Understand properties of linear function and slope & $5,8,12$ \\
\hline
\end{tabular}

\section{Data Analysis and Discuss}

Numeric data was collected with respect to participating pre-service teachers' particular knowledge and understanding in terms of linear function and slope by administering the DT instrument to participants.

The holistic view of participants' knowledge of linear function and slope was further examined by sorting them into six specific categories testing varying attributes regarding these two concepts. Table 2 categorizes all questions into appropriate categories and provides insights in subsequent data analysis. Thirteen items were compiled into six categories with distinctive attributes in relation to linear function and slope. In order to pinpoint participants' deficiencies and misconceptions correspondingly, both individual items and clustered category descriptive data reports were examined. As shown in Table 3, pre-service teachers mostly answered correctly Item 9 (62.79\%) on finding the slope of the $3 x-7 y=21$. In finding the slope of the line equation given in the algebraic representation form as $a x+b y=c$, it can be noticed that many students perceived the coefficient of " $x$ " as slope, as is the case in the form $y=m x+b$. For example, Moschkovich (1996) determined that a few 8th-grade students had difficulties regarding how to explain the functions of $x$-intercept, $y$-intercept, $\mathrm{m}$ and $\mathrm{b}$, and the interrelations with one another in a linear equation given as $y=\mathrm{m} x+\mathrm{b}$. These difficulties may be primarily explained by the fact that the students cannot associate different forms of representations of functions and may have not learned mathematical concepts comprehensively. This finding suggests that most students made mistakes in finding the slope of the line given in the algebraic form " $a x+b y=c$ " and they lacked conceptual understanding.

As question Item 11 (related to finding the slope of a line that contains points $(4,-6)$ and $(6,-7)$ ), only $37.21 \%$ of the students answered question Item 11 correctly. The result is consistent with the findings of Bar (1981), some students had difficulties in ordering the points $\left(x_{1}, y_{1}\right)$ and $\left(x_{2}, y_{2}\right)$ for computing the slope of a line $(\mathrm{m}=$ rise/run). Additionally, lack of calculation proficiency was as another prominent factor resulting in mistakes. Participants seemed to misunderstand the meaning of the parentheses here as an operational sign indicative of multiplication and exhibited an insufficient understanding of algorithm and properties of operations on numbers. This finding is consistent with the findings of She et al. (2014).

Item 7 is used to determine the midpoint of the line segment from the two points, which could be solved without knowledge of linear functions. It was performed correctly by slightly more than half of the participants, which was again a less than satisfactory result. These data analysis suggested that participating pre-service teachers possessed a limited knowledge in terms of linear function and slope. In order to pinpoint participants' deficiencies and misconceptions correspondingly, the researchers also request the participants not only answer the test, but also show their works. To further probe, the extent to pre-service teachers grasped those relevant 
ideas, and possible factors contributing to their incompetence in this regard, examining and analysis of participants’ work played a significant role in providing explanations.

Table 3

Percent of Correct Responses of on Six Category With Individual Item for DT

\begin{tabular}{lll}
\hline Category & Item No. & Percent (\%) \\
\hline 1. Determine the slope & 9 & 62.79 \\
2. Determine points on the linear function & 11 & 37.21 \\
& 3 & 34.88 \\
3. Find linear functions by using points & 7 & 55.81 \\
& 10 & 79.09 \\
4. Determine linear functions with perpendicular line & 13 & 41.83 \\
& 1 & 4.65 \\
5. Determine linear functions with parallel line & 2 & 16.28 \\
& 4 & 32.56 \\
6. Understand properties of linear function and slope & 6 & 25.58 \\
& 5 & 25.58 \\
\hline
\end{tabular}

The results presented in Table 3 revealed that problems pertinent to perpendicular linear functions received the lowest scores in performance (e.g., Items 1 and 2), which assessed the less commonly used perpendicular slope formula. The next lowest scores were associated with parallel linear functions (e.g., Items 4 and 6). Although the problem related to fundamental attributes of linear function (Item 5) received $25.58 \%$ of correctness, this was a far less than satisfactory result for pre-service teachers at this level. The data shows that most students had difficulties with transferring from algebraic representation to define linear function with the slope of a line. The findings displayed that some students had serious mistakes about the concept of the slope of a line because of their deficient or incorrect information. This study also indicated that most students had difficulties with linear function equations, graphs, and slopes, and did not translate between different representation modes of slope a line. As a result, no single one representation should be preferred and each of these representations should be encouraged by demonstrating the relationships between them. Students' understandings should be raised to the conceptual learning level by building reference to different types of representations (Nathan \& Kim, 2007; Rider, 2004). Furthermore, it was found that much confusion existed regarding the connection between the algebraic and geometric aspects of slope of a line. According to these findings, it can be stated that placing more importance on applications could enhance procedural learning in the teaching process.

The percent of correct response for six categories on DT with determining the slope, determining points on the linear function, finding linear function by using points, recognizing linear function with perpendicular line, determining linear function with parallel lines, and understanding properties of linear function and slope were $50.00 \%, 45.35 \%, 60.40 \%, 10.47 \%, 20.07 \%, 53.37 \%$, and 42.53\%, respectively. The lowest-scoring Item 1 for DT had the percent of correct response of determining linear function with perpendicular line 4.65\%, which represents that the most of participants were unfamiliar with the formula of slope in respect to perpendicular lines. 
Table 4 displays the percepts of correct responses and standard deviations on the DT by six categories for the 43 participants. The data shows that the percent of correct response of determining linear function with perpendicular line $10.47 \%$, determining linear function with parallel line $20.07 \%$ of DT was relatively low when compared with find linear function by using points (60.46\%), understand properties of linear function and slope (53.37\%). In this study, a passing benchmark of 70\% was considered to assess participants' content competency as a qualified elementary teacher's licensure for Minnesota Essential Academic Skills with Math. When $70 \%$ (9 items) of correctness was used as the passing rate of this instrument, only $11.6 \%$ of the pre-service teachers reached that standard. Derived from the DT, average number of items correctly answered by pre-service elementary teachers is 5.53 , the percentage of correctly responses is $42.53 \%$. In general, the pre-service elementary teachers performed rather inadequately on the DT. The results shown in Table 4 suggested that the participating teacher candidates possessed a poor understanding of content knowledge in this particular relevant content area, which may point to unsuccessful performance on the upcoming certification test and in subsequent teaching practice.

Table 4

Mean and Percent of Correct Responses of on Category Items for DT

\begin{tabular}{|c|c|c|c|c|c|}
\hline Category & $\begin{array}{l}\text { Number } \\
\text { of items }\end{array}$ & $\begin{array}{l}\text { Possible } \\
\text { scores }\end{array}$ & Mean & $\begin{array}{l}\text { Standard } \\
\text { deviations }\end{array}$ & Percent (\%) \\
\hline Determine the slope & 2 & 2 & 1.00 & 0.75 & 50.00 \\
\hline Determine points on the linear function & 2 & 2 & 0.91 & 0.68 & 45.35 \\
\hline Find linear function by using points & 2 & 2 & 1.21 & 0.74 & 60.46 \\
\hline Determine linear function with perpendicular line & 2 & 2 & 0.21 & 0.51 & 10.47 \\
\hline Determine linear function with parallel line & 2 & 2 & 0.58 & 0.73 & 20.07 \\
\hline Understand Properties of linear function and slope & 3 & 3 & 1.60 & 0.79 & 53.37 \\
\hline Total number of items & 13 & 13 & 5.53 & 6.01 & 42.53 \\
\hline
\end{tabular}

\section{Individual Item Analysis}

This study found pre-service elementary teachers, in general, do not have an adequate understanding of slope and linear functions. Participants received lowest scores within two categories: determine linear function with parallel line and determine linear function with perpendicular line. Within these two categories, based on these items were performed relatively poorly by many of the participants, such as Items 1 and 6 . Items 1 and 6 were selected for further discussions.

The results presented in Table 3 revealed that problem pertinent to perpendicular linear functions received the lowest scores in performance for Item 1, which assessed the less commonly used perpendicular slope formula. The data analysis strongly suggested that the participants were unfamiliar with the formula of slope in respect to perpendicular lines. Various misconceptions were also exposed during the review of the participants' written work. Quite a few individuals tried to identify the attribute of perpendicular slope by capitalizing on specific points on the non-homogeneous coordinate system.

In this study, the participating pre-service teachers tried to draw a corresponding homogeneous coordinate system in order to simulate the relationship between two perpendicular lines. In other words, arbitrary employment of concrete information without conceiving of its feasibility was a prevalent phenomenon in solving mathematical problems. Arbitrary utilization of numbers was detrimental and meaningless in solving this particular problem. In general, participants' works could be classified into four categories in accordance to 
levels of cognition: complete correct answer, false answer with correct direction of the slope, false answer without correct direction of the slope, and no answer, as shown in Table 5.

Table 5

Determine the Linear Function With Perpendicular Line

\begin{tabular}{llllc}
\hline$N=43$ & Correct answer & $\begin{array}{l}\text { False answer } \\
\text { with no work }\end{array}$ & $\begin{array}{l}\text { False answer } \\
\text { with correct direction of } \\
\text { the slope }\end{array}$ & $\begin{array}{l}\text { False answer } \\
\text { without correct direction } \\
\text { of the slope }\end{array}$ \\
\hline $\begin{array}{l}\text { Frequency } \\
\text { Percentage (\%) }\end{array}$ & 2 & 31 & 4 & 6 \\
\hline
\end{tabular}

The next lowest scores were associated with parallel linear functions Item 6 . Two lines in a plane that do not intersector meet are called parallel lines. In a Cartesian coordinate system, two parallel lines have the same slope. Geometrically, parallel lines are conceived as two lines sharing the same angle from the horizontal with different y intercepts. Algebraically, the expressions of parallel lines are identical in the coefficient of variable $x$ or $\mathrm{m}$, and divergent in the value of constant $\mathrm{b}$ (limited to $y=\mathrm{m} x+\mathrm{b}$ form). To understand the participating pre-service teachers' cognitive understanding in relation to parallel lines and corresponding properties, Items 6 was selected for further analyzing. Through dissecting the participants' written work, Item 6 consisted of: (a) assessing the participants' knowledge regarding slope of parallel lines and their capability to associate the linear function formula with particular points; and (b) not providing the algebraic equations for the original lines, which demanded the determination of the equation.

Table 6

Determine Linear Function With Parallel Line

\begin{tabular}{lllll}
\hline$N=43$ & Correct answer & $\begin{array}{l}\text { False answer } \\
\text { with no work }\end{array}$ & $\begin{array}{l}\text { False answer } \\
\text { with false the slope } \\
\text { and false } y \text {-intercept }\end{array}$ & $\begin{array}{l}\text { False answer with correct the } \\
\text { slope and false of } y \text {-intercept }\end{array}$ \\
\hline $\begin{array}{l}\text { Frequency } \\
\text { Percentage (\%) }\end{array}$ & 11 & 7 & 12 & 13 \\
\hline
\end{tabular}

One sixth of these pre-service teachers (16.28\%) apparently did not know or could not recall the how to find a parallel line. Almost half of the participants exhibited no understanding of the meaning of relation to parallel lines and corresponding properties (see Table 6), only 11 participants figured out correct answer. The results indicated that some pre-service elementary teachers exhibited problems in calculation proficiency by making mistakes for determining slope at the algorithmic level. Secondly, the data analysis of Item 6 revealed a prevalent phenomenon that some participants tended to misrepresent or misinterpret formulas and still others thought that $\mathrm{b}$ meant the $x$-intercept. Thirdly and most importantly, this study had uncovered the fact that a significant number of participating pre-service elementary teachers were unable to apply formulas or given conditions flexibly into varied contexts due to their lack of profound content knowledge in the examined category. This conclusion was drawn based on students' poor performance in Item 6. Considering the test difficulty level, this result was far less than satisfactory.

\section{Conclusions}

The data shows that average number of items correctly answered by pre-service elementary teachers is 5.53 , the percentage of correctly responses is $42.53 \%$. The results suggested that the participating teacher 
candidates possessed a poor understanding of content knowledge in this particular relevant content area, which may point to unsuccessful performance on the upcoming certification test and in subsequent teaching practice.

Based on the findings, several pre-service elementary teachers exhibited problems in calculation proficiency by making mistakes for determining slope at the algorithmic level; tended to misrepresent or misinterpret formulas and still others thought that $\mathrm{b}$ meant the $x$-intercept and a significant number of participating pre-service elementary teachers were unable to apply formulas or given conditions flexibly into varied contexts due to their lack of profound content knowledge in the examined category. The results of this study also indicated that many pre-service teachers had a limited understanding of the representation mode of the slope of a linear function. Their understanding about the slope was dominated by algebraic representations, while transformation between graphical and algebraic representations of slope was less understood. Rider (2004) recommended that in order to foster conceptual knowledge, linear functions should be taught with a method embracing multiple representations and providing linkages between these representations. Instructions should include multiple representations of functions allowed students to develop comprehensive and multifaceted conception of function (Rizzuti, 1991).

Another researcher suggested that teachers can support group work by discussing and sharing meanings about the slope of linear function to attain students' conceptual learning, and to correct students' possible misunderstandings (Moschkovich, 1996). Therefore, students should be provided with the opportunity to view many graphs and their corresponding equations and to examine the relationship between graphical representations and algebraic parameters. There can be several reasons for student's perceptions difficulties to learn, such as student background due to prior schooling or teacher's perceptions, instructional practices, content knowledge, or professional development. In particular, pre-service teachers have need of opportunities to investigate the concept of slope, to reflect on the definition of slope, to make connections among varied representations of slope and to examine linear functions, relation with parallel lines and perpendicular line and to explore linear functions involving with real world situations. In other words, teacher education programs need to assist pre-service teachers in building solid content knowledge, which may then result in a positive effect on student learning.

\section{References}

Acuna, C. (2007). Use of slope and $y$-intercept in prediction and description, as seen from students' perspective. In Proceedings of Third Conference of the European Society for Research in Mathematics Education, Bellaria, Italy.

Ball, D. L. (1988). Knowledge and reasoning in mathematical pedagogy: Examining what prospective teachers bring to teacher education (Unpublished doctoral dissertation, Michigan State University, East Lansing).

Barr, G. (1981). Some student ideas on the concept of gradient. Mathematics in School, 10(1), 14-17.

Davis, J. D. (2007). Real-world contexts, multiple representations, student-invented terminology, and Intercept. Mathematical Thinking and Learning, 9(4), 387-418.

Even, R. (1993). Subject-matter knowledge and pedagogical content knowledge: Prospective secondary teachers and the function concept. Journal for Research in Mathematics Education, 24, 94-116.

Hill, H. C., Rowan, B., \& Ball, D. (2005). Effects of teachers' mathematical knowledge for teaching on student achievement. American Educational Research Journal, 42(2), 371-406.

Kerslake, D. (1981). Graphs. In K. Hart (Ed.), Children's understanding of mathematics: 11-16 (pp. 120-136). London: John Murray.

Knuth, E. J. (2000). Student understanding of the Cartesian connection: An exploratory study. Journal for Research in Mathematics Education, 31, 500-507.

Leinhardt, G., Zaslavsky, O., \& Stein, M. K. (1990). Functions, graphs, and graphing: Tasks, learning, and teaching. Review of Educational Research, 60, 1-64. 
Ma, L. (1999). Knowing and teaching elementary mathematics: Teachers' understanding of fundamental mathematics in China and the United States. New Jersey, NJ: Lawrence Erlbaum Associates.

Moschkovich, J. (1996). Moving up and getting steeper: Negotiating shared descriptions of linear graphs. The Journal of the Learning Sciences, 5(3), 239- 277.

Nathan, M. J., \& Kim, S. (2007). Pattern generalization with graphs and words: A cross sectional and longitudinal analysis of middle school students’ representational fluency. Mathematical Thinking and Learning, 9(3), 193-219.

National Council of Teachers of Mathematics (NCTM). (2000). Principles and standards for school mathematics. Reston, VA: NCTM.

Norman, A. (1992). Teachers' mathematical knowledge of the concept of function. In G. Harel and E. Dubinsky (Eds.), The concept of function: Aspects of epistemology and pedagogy (MAA Notes, Vol. 25, pp. 215-232). Washington, DC: Mathematical Association of America.

Schoenfeld, A. H., Smith, J. P., \& Arcavi, A. (1993). Learning: The micro-genetic analysis of one student's evolving understanding of a complex subject matter category. In R. Glaser (Ed.), Advances in instructional psychology (Vol. 4, pp. 55-175). Hillsdale, NJ: Lawrence Erlbaum.

She, X., Matteson, S., Siwatu. K. O., \& Wilhelm, J. (2014). Exploring pre-service teachers' conceptual understanding of algebraic ideas: Linear function and slope. International Journal of Science and Mathematics Education, 1(5), 1209-1231.

Stump, S. L. (1996). Secondary mathematics teachers' knowledge of the concept of slope (Unpublished doctoral dissertation, Illinois State University, Normal, IL).

Rizzuti, J. M. (1991). Students’ conceptualizations of mathematical functions: The effects of a pedagogical approach involving multiple representations (Doctoral dissertation, Cornell University). Dissertation Abstracts International, 52-IOA, 549.

Rider, R. L., (2004, October). Using the SOLO taxonomy to evaluate student learning of function concepts in developmental algebra. Paper presented at The Annual Meeting of the North American Chapter of the International Group for the Psychology of Mathematics Education, Toronto, Canada. Retrieved from http://www.allacademic.com/meta/p117607_index.html

Rowan, B., Chiang, F. S., \& Miller, R. (1997). Using research on employees' performance to study the effects of teachers on students' achievement. Sociology of Education, 70, 256-284.

Zaslavsky, O., Sela, H., \& Leron, U. (2002). Being sloppy about slope: The effect of changing the scale. Educational Studies in Mathematics, 49, 119-140.

Wilson, M. R. (1994). One pre-service secondary teacher's understanding of function: The impact of a course integrating mathematical content and pedagogy. Journal for Research in Mathematics Education, 25, 346-370. 